\title{
Estágio Supervisionado em Psicologia Escolar: Desmistificando o Modelo Clínico ${ }^{1}$
}

Supervised Training Course in School Psychology:

"Demystifying" the Clinical Model

Prácticas Supervisadas en Psicología Escolar:

Desmitificando el Modelo Clínico

Maria de Fátima

Evangelista Mendonça Lima

Universidade Federal de Mato Grosso do Sul
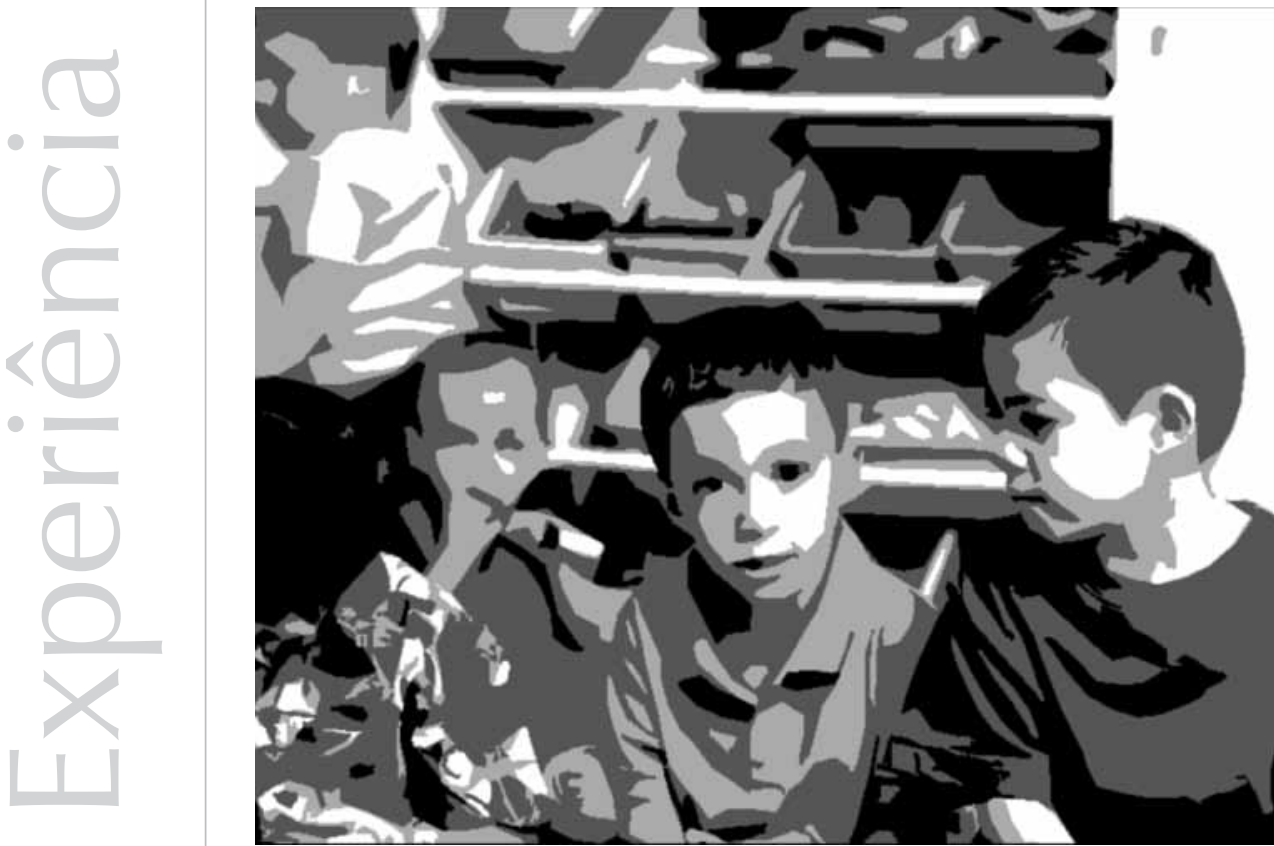
Resumo: O objetivo deste relato é apresentar a prática de Estágio Supervisionado em Psicologia Escolar da UFMS, desenvolvida em unidades de CEINFs (Centros de Educação Infantil) de Campo Grande, MS. O estágio teve como objetivos: o conhecimento e a análise do espaço institucional de educação infantil, o reconhecimento da especificidade da atuação psicológica e o planejamento da intervenção. A prática de estágio foi desenvolvida por meio de visitas semanais às instituições, de aproximadamente $2 \mathrm{~h}$, e supervisão semanal de $4 \mathrm{~h}$ aula. O relato aponta principalmente a presença de comportamentos cristalizados quanto ao papel do psicólogo escolar, assim como os principais desafios que se apresentam no caminho rumo a um atendimento educacional consistente e coerente à criança de 0 a 6 anos de idade, em creches e pré-escolas. Palavras-chave: Estágio supervisionado. Psicologia escolar/educacional. Educação infantil.

Abstract: The aim of this report is to present the practice of supervised training in educational psychology at the UFMS, Federal University of Mato Grosso do Sul, as developed in the CEINFS (Centers for Infant Education) of Campo Grande, MS. The training had as objectives: knowledge and analysis of the institucional space of infant education, recognition of the specificity of the activity of psychologists and the planning of interventions. The practical period of training was developed by weekly visits to the institutions of approximately 2:00 $\mathrm{h}$ and weekly supervision of 4:00 h lesson. It mainly points the presence of crystallized behaviors in relation to the role of the school psychologist, as well as the main challenges that are present in a coherent and consistent educational attendance to the child up to 6 years old, in day-care centers and nursery schools. Keywords: Supervised training. School/education psychology. Infant education.

Resumen: El objetivo de este relato es presentar la práctica de Cursillo Supervisado en Psicología Escolar de la UFMS, desarrollada en unidades de CEINFs (Centros de Educación Infantil) de Campo Grande, MS. Las prácticas tuvieron como objetivos: el conocimiento y el análisis del espacio institucional de educación infantil, el reconocimiento de la especificidad de la actuación psicológica y la planificación de la intervención. La práctica de las prácticas fue desarrollada por medio de visitas semanales a las instituciones, de aproximadamente $2 \mathrm{~h}$, y supervisión semanal de $4 \mathrm{~h}$ clase. El relato señala principalmente la presencia de comportamientos cristalizados en cuanto al papel del psicólogo escolar, así como los principales desafíos que se presentan en el camino rumbo a un servicio educacional consistente y coherente al niño de 0 a 6 años de edad, en guarderías y pre-escuelas.

Palabras clave: Prácticas supervisadas. Psicología escolar/educacional. Educación infantil.

O Estágio Supervisionado em Psicologia Escolar, do Curso de Psicologia da UFMS, é integrante da estrutura curricular e tem como objetivos: propiciar a formação técnico-profissional, integrar a teoria e a prática através de vivência de experiência o mais próximo possível de situações reais e propiciar maior contato com a área da educação.

O referido estágio supervisionado, composto de três fases, é desenvolvido no espaço de dois anos, tendo o Estágio I 34 horas de duração(semestral), o Estágio II, 34 horas (semestral), e o Estágio III, 102 horas de duração (anual).

Especificamente, os objetivos do Estágio Supervisionado em Psicologia Escolar II, desenvolvido em 34 horas, foram: (1) propiciar a discussão sobre o espaço institucional da educação infantil no qual se insere o profissional de Psicologia e (2) favorecer o reconhecimento da especificidade de atuação psicológica e a busca do planejamento da intervenção da Psicologia escolar no campo da educação infantil.

Pensar nesses objetivos é entender que a Psicologia pode oferecer seus conhecimentos para a área da educação em geral e da educação infantil em particular, atingindo pais, crianças e profissionais que ali atuam.

Sabemos que há conflitos e tensões na aproximação entre a Psicologia e a educação, mas isso não implica negação da participação e da contribuição da ciência psicológica para a educação. Segundo Urt, "a contribuição da Psicologia para a educação infantil deve 
centrar-se em uma base primordial: é preciso conhecer quem aprende e como se desenvolve" (p. 13).

O desenvolvimento da criança é o processo de apropriação da evolução histórica da humanidade, que se realiza através das trocas estabelecidas com os adultos nas condições de ensino. $\mathrm{O}$ desenvolvimento da psique de uma criança é determinado diretamente pela sua própria vida, isto é, pelas condições concretas que possibilitam interações e relações possíveis (Urt, 2006).

Assim, o homem se transforma de biológico em histórico-cultural. Nessa perspectiva vigotskiana, o meio cultural, no qual a criança vive, é que lhe oferece as formas de descobrir e organizar o real, de conhecer a si mesma e o meio que a cerca e de operar sobre ele, o que significa dizer que os sistemas de representação da realidade vêm do social (Souza, 2003).

Como nos mostra Rocha (1999), a Psicologia, pouco a pouco, vem se instalando no debate acadêmico referente à educação infantil no Brasil.

A partir da produção acadêmica produzida no Brasil, é possível pensar em orientações para a educação da criança de 0 a 6 anos de idade diferentes dos parâmetros pedagógicos estabelecidos a partir da infância em situação escolar. Nesse modelo, segundo Rocha (1999),

Mantém-se a passagem da infância de um âmbito familiar para um institucional, a creche, que, co-responsabilizando-se pela criança, passa, também, a criar uma linguagem própria sobre as condições das crianças em seu interior bem como da configuração dos profissionais que nela vão atuar. Diferenciam-se escola e creche essencialmente quanto ao sujeito, que, nesse último caso, é a criança, e não o sujeitoescolar (o aluno), e, quanto à definição de suas funções, ao contrário daquelas (que têm se constituído historicamente como uma pedagogia escolar), suas funções aqui se encontram em processo de constituição. Uma Pedagogia da infância e da educação infantil necessita considerar outros níveis de abordagem de seu objeto: a criança em seu próprio mundo, uma vez que se ocupa, fundamentalmente, de projetar a educação desses novos sujeitos sociais. (p. 50)

Acreditamos que a Psicologia possa colaborar com essa transformação, se tiver o comprometimento de pôr à vista o aparente e desocultar o real. O rompimento com algumas concepções cristalizadas é um dos caminhos (Urt, 2006).

Assumimos esse enfoque da Psicologia na instituição educacional creche/pré-escola. Essa perspectiva busca uma prática preventiva e de promoção, seja da aprendizagem, seja do desenvolvimento global da criança, seja dos conteúdos transmitidos. Defendemos uma atuação abrangente, organizada, que envolva não apenas a relação educador(a)/ professor(a)/criança mas também as articulações entre os educadores e os demais profissionais, procurando fazer uma conexão com os determinantes sociais e estimulando a interface com a Sociologia, a Pedagogia, a Filosofia, a História, a Antropologia, a biologia, a política, o serviço social, as artes, etc. É uma atuação que envolve a instituição creche/ pré-escola em sua totalidade, apresentando formas de ação e intervenção baseadas na realidade e no contexto da escola e enfatizando a descentralização da análise da criança tomada individualmente, para a instituição escolar em sua totalidade.

Trata-se de um modelo de estágio interacional, que abrange a relação criança-instituiçãofamília-sociedade. O psicólogo escolar, nesse sentido, seria um educador, atuando de forma conjunta com outros profissionais, primando pelo aspecto inter-relacional e respeitando o contexto sociocultural da instituição e das pessoas com as quais se relaciona. Além do mais, deve traduzir as reflexões conjuntas em ações concretas a serem assumidas pelos envolvidos no processo ensino-aprendizagem, não perdendo de vista os conteúdos veiculados com as experiências das crianças e com a análise da família, da instituição creche/pré-escola e da sociedade. 
Vem sendo delineada uma outra prática no que se refere ao cuidado e à educação da criança de 0 a 6 anos, configurando um novo modelo de educação, diverso das práticas assistencialistas e paternalistas que vigoraram desde a II Guerra Mundial (Lima, 2004).
Após a II Guerra Mundial, economistas, educadores/as, psicólogos/as, assistentes sociais, juristas, sociólogos/as e antropólogos passaram a considerar que a educação e o cuidado de crianças pequenas constitui um bem individual, familiar e social, e que a educação e o cuidado da criança pequena devem compartilhados, em período diuturno, pela família e por uma instituição coletiva. Vem sendo delineada uma outra prática no que se refere ao cuidado e à educação da criança de 0 a 6 anos, configurando um novo modelo de educação, diverso das práticas assistencialistas e paternalistas que vigoraram desde a II Guerra Mundial (Lima, 2004).

Assim, no Brasil, como em outros países, a educação infantil passou a ser reconhecida como um direito, tanto da criança quanto de sua família. A partir da Constituição de 1988, a educação infantil constitui-se na primeira etapa da educação básica, passando a ser um dever do Estado e um direito da família. A LDB (Lei de Diretrizes e Bases da Educação), de 1996, institui que a educação infantil, que integra a educação básica com o ensino fundamental e médio, seja desenvolvida em creches (crianças de 0 a 3 anos) e préescolas (crianças de 4 a 6 anos), e que sejam atendidas as necessidades da criança no tocante ao cuidado e à educação.

As crianças dessa faixa etária têm necessidade de alimentação, atenção, carinho, segurança e proteção, sem os quais não conseguiriam sobreviver. Nessa etapa, também, as crianças tomam contato com o mundo que as cerca, por meio das experiências diretas com as pessoas e as coisas desse mundo e com as formas de expressão que nele se manifestam.

Nesse contexto, a organização do espaço físico das instituições de educação infantil constitui-se em aspecto importante a ser pensado, devendo-se levar em consideração todas as dimensões humanas potencializadas nas crianças: o imaginário, o lúdico, o artístico, o afetivo e o cognitivo, entre outras (Faria \& Palhares, 2005).
Como nos lembram esses autores, tais dimensões estão contempladas no documento Critérios para atendimento em creches e préescolas que respeitem os direitos fundamentais da criança, elaborado por Rosemberg e Campos (COEDI/MEC, 1995). O referido documento defende a idéia de

\begin{abstract}
que as instituições de educação infantil possam verdadeiramente oportunizar (como dizem os italianos) ambientes de vida em contexto educativo, onde as crianças possam expressar, nas mais diferentes intensidades, suas cem linguagens, conviver com todas as diferenças (de gênero, de idade, de classe, de religiões, de etnias e culturas etc.), combatendo as desigualdades, exercitando a tolerância (e não o conformismo), a solidariedade, a cooperação e todos os comportamentos e valores de caráter coletivo, concomitantemente com a construção da sua identidade e autonomia, sentido de pertencimento à comunidade local, enquanto especificidade infantil, e, ao mesmo tempo, preparando-se para as outras fases da vida que também são tão provisórias quanto a infância, aprendendo dessa forma a arbitrariedade e provisoriedade da hierarquia social existente na sociedade atual. (Faria \& Palhares, 2005, p. 75)
\end{abstract}

O fato de se considerar que a educação infantil envolve, ao mesmo tempo, cuidar e educar vai ter conseqüências profundas na organização das experiências que ocorrem nas creches e pré-escolas, dando-lhes características que vão marcar sua identidade como instituições que são diferentes não só da família mas também da escola fundamental (Craidy \& Kaercher, 2001).

Colocados os pressupostos orientadores de nosso trabalho, apresentaremos, a seguir, o desenvolvimento da prática de estágio.

\section{O contexto dos CEINFs}

Desde a LDB, em 1996, a educação infantil é responsabilidade do governo municipal. Em Campo Grande, MS, o atendimento à criança pequena através de creches e pré-escolas passou para o âmbito da prefeitura apenas 
em 2007, apesar de a LDB estabelecer essa responsabilidade em 1996.

A partir do governo de André Puccinelli, os antigos CEls (Centros de Educação Infantil), vinculados à SETA (Secretaria de Estado de Trabalho e Assistência Social), foram transferidos para o âmbito da Prefeitura, tornando-se CEINFs, vinculados à Secretaria Municipal de Assistência Social (SAS), continuando, assim, no campo da assistência social. São constituídos fisicamente por dois tipos de construções: adaptadas e específicas para a atuação da educação infantil.

O debate sobre a vinculação da educação infantil à assistência social é antigo entre educadores/as, professores/as e pesquisadores/ as. A discussão gira em torno do fato de a educação infantil estar vinculada ao âmbito da assistência para servir como forma de controle da pobreza, imprimindo a identidade de uma instituição para os pobres, e não de uma instituição para todos, como deve ser.

Atualmente, a Prefeitura de Campo Grande conta com 87 CEINFs, atendendo cerca de 12.000 crianças. O Fundeb (Fundo de Manutenção e Desenvolvimento da Educação Básica e de Valorização dos Profissionais) cobre financeiramente cerca de 2/3 das crianças atendidas pela SAS, segundo informação dessa Secretaria.

Os Municípios recebem os recursos com base no número de alunos da educação infantil e do ensino fundamental. Somente a partir de 2009 é que o Fundo estará funcionando com todo o universo de alunos da educação básica pública presencial, e os percentuais de receita que o compõem terão alcançado o patamar de $20 \%$ de contribuição (Brasil, 2008).

Desses CEINFs, 26 vieram do Estado, são os antigos CEls. Desses 87, 3 são mantidos por convênio entre o Banco do Brasil, o SESI e a Secretaria Municipal de Assistência Social (SAS), que cede professores e outros funcionários. Além disso, integram os CEINFs um total de 27 ONGs (organizações nãogovernamentais). Funcionam também em convênio com a Secretaria Municipal de Assistência Social, que cede funcionários, material de limpeza e assessoria pedagógica.

Para funcionamento e acompanhamento pedagógico dessas instituições, existe um termo de gestão compartilhado entre Secretaria Municipal de Assistência Social (SAS) e Secretaria Municipal de Educação (SEMED). A SEMED elabora as diretrizes para atuação, além de ceder os professores, mas a proposta pedagógica e o acompanhamento ficam a cargo da SAS.

Os documentos que norteiam a ação da educação infantil na SAS, segundo os/as dirigentes, são: Referencial Curricular Nacional para a Educação Infantil (1998), Parâmetros Curriculares Nacionais (1998), Diretrizes Curriculares Nacionais para a Educação Infantil (1998), Parâmetros Nacionais de Qualidade para a Educação Infantil (2006), Parâmetros Básicos de Infra-Estrutura para Instituições de Educação Infantil (2006).

Não foi possível constatar a existência de proposta pedagógica nos CEINFs. A discussão, hoje, centra-se na autonomia de cada instituição educacional para elaborar e desenvolver seu projeto pedagógico e na necessidade de que esse projeto se comprometa com padrões de qualidade.

\section{A organização dos grupos de alunos/as}

Para o desenvolvimento do estágio, os alunos foram encaminhados aos CEINFs. Optamos por organizar os 20 alunos em duplas e trios de maneira que, juntos, pudessem realizar uma observação mais ampla de todos os aspectos inerentes ao propósito da organização. Em função da carga-horária reduzida, cada dupla ou trio realizou o estágio em apenas um CEINF, tendo feito cerca de 10 visitas. 


\section{O espaço de realização da prática de estágio}

Cada uma das instituições apresenta suas especificidades, dadas as peculiaridades de sua abrangência e localização. Em geral, atendem crianças de baixo poder aquisitivo. A dinâmica de trabalho depende, em grande parte, da figura da diretora, isto é, de suas características, temperamento e atitudes.

Considerando ser a primeira vez que os/as alunos/as do Curso de Psicologia da UFMS teriam contato, na prática, com a educação infantil, ao entrar em contato com os CEINFs, o primeiro passo foi conhecer sua realidade. Para isso, a diretora foi entrevistada. O objetivo era conhecer a instituição, a disposição em receber alunos/as de Psicologia, a proposta pedagógica, a dinâmica de atuação, as condições de trabalho dos(as) professores, a lista de espera das crianças e o respeito ao direito da família pela creche e pré-escola, entre outros aspectos. Em seguida, passaram para o conhecimento dos documentos da instituição.

Após isso, o passo seguinte foi a observação. Para o desenvolvimento da observação, orientamos os/as alunos/as para que fizessem uso de um protocolo de observação, de modo a garantir que fossem consideradas algumas dimensões: a interação professor/educador(a)/ criança, criança/criança, instituição-família, tipo de atividade (se dirigida, livre, de criatividade, etc), a organização do espaço, condições materiais de realização da atividade (utilização de material pedagógico, sucata, espaço físico, etc), alimentação, iluminação, número de crianças, rotina de trabalho e, por fim, as considerações pessoais sobre a observação realizada.

As observações foram realizadas nos diversos níveis de atendimento (berçário e níveis I, II e III), contemplando, assim, as crianças de 0 a 5 anos de idade, considerando que, a partir de 5 anos de idade, as crianças estão sendo encaminhadas para o ensino fundamental, mesmo que a LDB considere que a educação infantil engloba as crianças de 0 a 6 anos. Isso está ocorrendo em Campo Grande por força de liminar de juiz de Direito, que entende que a criança nessa faixa etária já deve estar freqüentando aquele nível de ensino. Na opinião de especialistas, professores e pesquisadores, essa antecipação da escolarização da criança pequena pode trazer riscos para a sua aprendizagem e desenvolvimento (Oliveira, 2002).

Uma de nossas preocupações com o desenvolvimento do estágio foi a de levar os/as estudantes a estabelecerem ligações entre a teoria e a prática, fundamentando-se continuamente. No decorrer das observações, os/as estudantes destacaram temáticas que pudessem propiciar uma revisão de literatura, de forma a ampliar seus conhecimentos e também a adquirir consciência de sua importância para a aprendizagem e o desenvolvimento infantil.

Alguns aspectos foram levantados na fase de observação. Do cenário de dificuldades levantadas, uma delas mereceu maior preocupação de nossa parte: a relação estabelecida entre Psicologia e educação infantil. Por isso, escolhemos esse tema para maior aprofundamento na devolutiva com os professores/educadores, tomando-o como ponto de partida para as discussões.

O que mais chamou a atenção é a grande ênfase no modelo clínico da Psicologia escolar. Os alunos foram mobilizados, em um primeiro momento, para darem conta de problemas comportamentais apresentados pelas crianças - segundo os/as professores/as e educadores/as, indisciplina, hiperatividade, carência afetiva, suposição de maus tratos, etc. Em outras palavras, a necessidade dos professores/educadores era a de que essas crianças fossem atendidas individualmente pelos alunos, no sentido de adequação de seus comportamentos. É como se a função do psicólogo escolar fosse consertar o que se 
A tendência histórica da Psicologia, no Brasil, é a de uma atuação voltada para a função e o trabalho clínico, que coloca como ação básica análise, diagnóstico e tratamento dos problemas de caráter emocional, geralmente, de forma individualizada (Azevedo, 2000; Bock, 2003). encontra "estragado" no aluno (neste caso, a criança).

A tendência histórica da Psicologia, no Brasil, é a de uma atuação voltada para a função e o trabalho clínico, que coloca como ação básica análise, diagnóstico e tratamento dos problemas de caráter emocional, geralmente, de forma individualizada (Azevedo, 2000; Bock, 2003).

Essa Psicologia, segundo Bock, se desenvolveu e se fundamentou em concepções universalizantes e naturalizantes da subjetividade. Nessa perspectiva, a sociedade surge como se se contrapusesse aos movimentos naturais do ser humano; é algo oposto aos interesses naturais do homem. A Psicologia assim concebida abandona qualquer vínculo mais aprofundado com a realidade social e cultural para considerar o homem de forma isolada, ou seja, independentemente da relação com o mundo cultural que o constitui.

Essa forma de entendimento da Psicologia vai corresponder às expectativas dos CEINFs. Em outras palavras, a visão é a de que a função da Psicologia na escola é elaborar diagnósticos das crianças e tratá-las, para adequá-las, em vez de realizar um trabalho de desconstrução de representações, de reflexão junto ao professor e à criança sobre as relações estereotipadas existentes na instituição, fundamentadas em crenças que colocam o distúrbio de comportamento da criança como ponto central.

Outro aspecto levantado é a diferença de atendimento entre creche e pré-escola. A diferença é estabelecida na medida em que há disponibilidade de professores com curso superior para atender o nível de pré-escola (4 e 5 anos de idade), enquanto, no nível da creche (0 a 3 anos), em geral, são educadores/ as de nível médio, ou, às vezes, auxiliares, que atuam nas diversas atividades, tais como: cozinha, limpeza, etc. Isso mostra a relutância em oferecer atendimento à criança de 0 a 3 anos, o que tem sido denunciado por pesquisadores (Rosemberg, 2002).

Merece ainda ser citada a dificuldade de professores/educadores em lidarem com a expressão de afetividade das crianças. Por exemplo, com a sexualidade, a movimentação exacerbada, a teimosia, a agressividade, etc. Os professores/educadores, em geral, expressam uma visão patológica com relação a esses comportamentos, talvez por desconhecerem o desenvolvimento infantil; daí a utilização freqüente do senso comum.

Oliveira (2002) chama a atenção para o fato de creches e pré-escolas estarem preocupadas com a construção de uma proposta pedagógica que julgam progressista, orientada primordialmente para o desenvolvimento cognitivo, entendido de maneira muito restrita, negando-se, por exemplo, a função do afeto nesse processo.

Os professores/educadores também manifestaram a insatisfação com os baixos salários, a falta de material pedagógico, de espaço físico e de um número maior de professores/educadores para o desenvolvimento de atividades com as crianças. Em geral, o material utilizado é a sucata, principalmente os brinquedos. Além disso, muitas atividades planejadas não podem ser desenvolvidas por falta de espaço físico, de material e de pessoal, o que faz com que as crianças permaneçam por muito tempo em frente à televisão.

Souza (1996) argumenta sobre a importância do brincar e da linguagem para o desenvolvimento da criança.

Quando a criança brinca, ela normalmente mostra no jogo um comportamento mais sofisticado do que aquele que ela apresenta na vida diária. No jogo, a criança demonstra a consciência que possui das regras e dos valores de convívio com a realidade. Porém, mais do que se confrontar e reproduzir essas regras, a criança reelabora-as criativamente, combinando-as entre si e edificando com 
elas novas possibilidades de interpretação e representação do real. (p. 53)

Vigotski (1984) chamou de zona de desenvolvimento proximal o comportamento que a criança evidencia no jogo, mas que dificilmente transparece na vida diária. Esses comportamentos são o suporte da estruturação dos valores morais, éticos, afetivos e cognitivos que, mais tarde, irão modelar suas possibilidades de subjetividade diante do contexto social e cultural em que vive (Souza, 1996).

A rivalidade entre mães e educadores/as é outro fator evidenciado. Para as professoras/ educadoras, as mães não cuidam das crianças como elas: as crianças vêm sujas, com roupa sem lavar, com piolho, etc, isto é, há uma culpabilização das mães por não cuidarem dos filhos. Por outro lado, elas dizem que sabem que os pais reclamam delas, falam que não fazem nada o dia inteiro. A rivalidade tanto das educadoras para com as mães quanto das mães para com as educadoras é um assunto bastante discutido na literatura desde a segunda metade da década de 1980 (Haddad, 1991).

Para Mattioli (1989), esse comportamento parece ter como conseqüência a ambigüidade de ambas em relação ao desempenho de seus próprios papéis. Nesse sentido, Bloch e Buisson (1998) afirmam que essa relação complicada é resultado da norma social da "boa mãe", isto é, existe no ideário feminino a crença de que a mãe deve permanecer em casa inteiramente à disposição dos filhos, sob pena de estar causando prejuízo ao desenvolvimento emocional da criança; nesse sentido, a mãe que não cuida do filho é culpabilizada pela ausência, não podendo ser considerada uma "boa mãe". Por outro lado, as mães que não cuidam, elas próprias, dos filhos rivalizam com as cuidadoras por medo de perderem o amor dos filhos.

Ao final do estágio, foi elaborada a devolutiva para os professores/educadores e diretora, que teve como objetivo possibilitar a reflexão sobre as práticas no âmbito de uma instituição escolar que atende crianças pequenas, isto é, acerca da função da Psicologia na escola, da própria instituição escolar, cujo conteúdo o professor/educador está desenvolvendo, e que vai fazer com que as crianças ampliem a capacidade de pensar, de se conhecer e de conhecer e organizar a realidade e, com isso, transformá-la. Como a criança aprende e se desenvolve? Como elabora o pensamento? Qual o papel da linguagem no desenvolvimento? Qual seria a direção da educação? Qual a função do/a professor/a? Para onde a educação deve se dirigir? Quem decide o que é bom para a criança? Quais os valores que devem nortear essa ação?

Dessa forma, a devolutiva pretendeu, principalmente, mobilizar professores/ educadores e diretora para a reflexão, a re-significação e para a produção de novos sentidos sobre a Psicologia em geral e, em particular, a Psicologia escolar e educacional.

Enfim, o objetivo foi o de deixar nossa contribuição aos professores/as, de maneira que pudessem conhecer alguns dos pressupostos que fundamentaram o trabalho sistematizado pelo grupo.

\section{Considerações finais}

A primeira conclusão a que poderíamos chegar é sobre a necessidade de intervenção junto aos professores/educadores no sentido de sua formação. Pensamos que, ao mesmo tempo em que temos que considerar as condições materiais que as instituições de 
educação infantil ainda enfrentam, tais como falta de material, de pessoal e de espaço físico, temos que considerar também a formação do professor/educador, de vez que os fatos não são excludentes.

Considerar uma intervenção junto a professores significa considerar a totalidade institucional e, mais do que isso, refletir sobre a própria sociedade. Segundo Leão (2008), o projeto que chega na escola é um projeto de sociedade. Nesse sentido, não podemos deixar de lado o fato de que as práticas exercidas pelos professores/educadores têm como elemento constitutivo concepções, nem sempre explicitadas, do que é educação, do que se espera da instituição escolar e do aluno, no caso aqui, a criança pequena.

A Psicologia pode contribuir com tal tarefa. Apesar de essa ciência ter legitimado a desigualdade social ao recorrer ao discurso das diferenças individuais, classificando os indivíduos em mais aptos ou menos aptos, assim como favorecendo a adaptação dos indivíduos na sociedade, ela pode desempenhar um papel diferente, já que se desenvolveu como ciência conforme a vida social foi exigindo esse tipo de saber e fazer (Bock, 2003; Urt, 2006).

Outra conclusão a que poderíamos chegar é que, apesar das não recentes críticas a respeito da relação entre a Psicologia e a educação, na escola (Patto, 1990; Urt, 2000), vemos que na educação infantil se repete a visão de que a função do psicólogo é medir habilidades e diagnosticar os alunos.

De acordo com Facci (2008), só faz sentido o trabalho do psicólogo na escola se ele tiver consciência de que vai colaborar na função da escola, que é levar o aluno a se apropriar do conhecimento científico produzido na humanidade. Assim, a função do psicólogo é, muitas vezes, lidar com o sofrimento daquele que não consegue aprender, assim como mostrar ao professor/a como se dá a aprendizagem do/a aluno/a, ou seja, qual a relação entre o desenvolvimento e a aprendizagem. Enfim, deve procurar entender como o professor/a está ensinando e como o aluno/a está aprendendo.

Contudo, observamos que os/as professores/as concebem a Psicologia como um instrumento de ajustamento ao meio. Vivenciam o processo de "patologização" das questões educacionais: o psicólogo é visto como um especialista em adaptação: do desvio à norma, da fantasia à realidade.

Por fim, levar em conta as condições materiais inclui levar em consideração a existência de material e organização do espaço físico. Isso indica, como argumentam Faria e Palhares (2005), a necessidade de repensar a organização espacial comumente adotada entre nós, inspirada em um único tipo de escola/sala de aula, da casa e do hospital, que, muitas vezes, não abrange todas as dimensões humanas e nem atende todos os quesitos imprescindíveis para a educação e o cuidado das crianças pequenas em espaço coletivo.

A realização dessa experiência foi vista por nós como um momento de aprendizagem coletiva, uma vez que se tratou da primeira experiência de estágio supervisionado do curso de Psicologia em instituição de educação infantil, ou seja, com crianças de 0 a 6 anos de idade. Todos nós fizemos descobertas que, ao longo do processo, colaborou para que reelaborássemos nossas ações. Temos a certeza de que todos/as os/ as envolvidos/as puderam beneficiar-se, adquirindo novos conhecimentos, ampliando outros e, principalmente, contribuindo para a mudança qualitativa do dia a dia das crianças. 


\section{Maria de Fátima Evangelista Mendonça Lima}

Doutora em Psicologia social pela PUC/SP, professora da Universidade Federal de Mato Grosso do Sul (UFMS).

\section{Endereço para envio de correspondência:}

Rua Domingos Marques, 903 - Jardim Bela Vista - Campo Grande - MS - Brasil, CEP: 79003-190

E-mail: fatimamlima10@uol.com.br

Recebido 20/08/2008 Reformulado 08/01/2009 Aprovado 15/01/2009

\section{Referências}

Azevedo, A. C. P. (2000). Psicologia escolar: o desafio do estágio. Lorena, SP: Editora Stiliano.

Bloch, F., Buisson, M. (1999). La disponibilité à l'enfant: le don et la norme. Recherches et Prévisions, (57/58), 17-29.

Bock, A. M. B. (2003). A psicologia hoje: formação, ciência e profissão. In I. B. Leão (Org.), Educação e psicologia: reflexões a partir da teoria sócio-histórica (pp. 13-24). Campo Grande: Editora UFMS.

Brasil. MEC/SEB (1998). Parâmetros Curriculares Nacionais.

Brasil. MEC/SEB (1998). Referencial Curricular Nacional para a Educação Infantil.

Brasil. MEC/SEB (2006). Parâmetros Nacionais de Qualidade para a Educação Infantil.

Brasil. MEC/SEB (2006). Parâmetros Básicos de Infra-Estrutura para Instituições de Educação Infantil.

Critérios para atendimento em creches e pré-escolas que respeitem os direitos fundamentais da criança. (1995). Ministério da Educação e do Desporto, Secretaria de Educação Fundamental, Coordenadoria Geral de Educação Infantil, COEDI, Brasília.

Definição, Composição, Caracterização e Vigência do Fundeb. (2008). Ministério da Educação, Secretaria de Educação Básica. Disponível em: <http://portal.mec.gov.br/seb/index. php?option $=$ content\&task $=$ view\&id $=800 \&$ Itemid $=840>$ Acessado em 5 de jan. 2009.

CNE/CBE. (1998). Diretrizes Curriculares Nacionais para a Educação Infantil. Ministério da Educação, Secretaria de Educação Básica, Parecer CEB/CNE no 022/98, Brasília.

Lei Federal n. 9.394, de 20 dez. 1996. Lei de Diretrizes e Bases da Educação, Brasília.

Craidy, C., \& Kaercher, G. E. (2001). Educação infantil: Pra que te quero? Porto Alegre: Artmed.

Facci, M. G. D. (2008). Notas sobre o I Encontro Regional de Psicologia Escolar e Educacional. Campo Grande: CRP/14a Região, MS/MT.

Faria, A. L. G., \& Palhares, M. S. (2005). (Eds.), Educação infantil pós LDB: rumos e desafios. Campinas, SP: Autores Associados.
Haddad, L. (1991). A creche em busca de identidade. São Paulo: Edições Loyola.

Leão, I. B. (2008). Notas sobre o I Encontro Regional de Psicologia Escolar e Educacional. Campo Grande: CRP/14a , Região MS/MT.

Lima, M. de F. E. M. (2004). A demanda e escolha das mães por educação infantil: um novo tema para o estudo da educação infantil. Tese de Doutorado em Psicologia Social, Pontifícia Universidade Católica de São Paulo, São Paulo.

Mattioli, O. C. (1988). No reino da ambigüidade. Dissertação de Mestrado em Psicologia Clínica, Pontifícia Universidade Católica de São Paulo, São Paulo.

Oliveira, Z. R. (2002). Educação infantil: fundamentos e métodos. São Paulo: Cortez.

Patto, M. H. S. (1990). A produção do fracasso escolar: histórias de submissão e rebeldia. São Paulo: T. A. Queiroz.

Rocha, E. A. C. (1999). A pesquisa em educação infantil no Brasil: trajetória recente e perspectivas de consolidação de uma pedagogia. Florianópolis: UFSC.

Rosemberg, F. (1996). Contemporary trends and ambiguities $\mathrm{em}$ the upbringing of small children. In Brazilian issues on education, gender and race (pp. 87-110). São Paulo: FCC.

Rosemberg, F. (2002). Organizações multilaterais, Estado e políticas de educação infantil. Cadernos de Pesquisa, 115, 25-63.

Souza, S. J. (1996). Re-significando a psicologia do desenvolvimento: uma contribuição crítica à pesquisa da infância. In S. Kramer, \& M. I. Leite (Orgs.), Infância: fios e desafios da pesquisa (pp. 39-55). Campinas, SP: Papirus.

Souza, T. B. (2003). A prática pedagógica a partir dos pressupostos teóricos de Vigotski. In I. B. Leão (Org.), Educação e psicologia: reflexões a partir da teoria sócio-histórica. (pp. 175-191). Campo Grande: Editora UFMS.

Urt, S. da C. (2000). Psicologia e práticas educacionais. Campo Grande, MS: Editora UFMS.

Urt, S. da C. (2006). A psicologia e a(o) professor(a) de educação infantil. Consórcio Pró-Formar/SED/MEC. Cuiabá: Editora UFMT.

Vigotski, L. S. (1984). Pensamento e linguagem. São Paulo: Martins Fontes. 